\title{
Role of who modified partograph in management of spontaneous labour in primigravidas
}

\author{
Sowmya Gopinath ${ }^{1}$, Dhananjaya B $\mathrm{S}^{2, *}$, Chandhana Krishna ${ }^{3}$ \\ ${ }^{1,3}$ Assistant Professor, ${ }^{2}$ Professor and HOD, ${ }^{1,2}$ Dept. of Obstetrics and Gynecology, ${ }^{3}$ Dept. of Community Medicine, Sree \\ Siddhartha Medical College, Tumkur, Karnataka, India \\ *Corresponding Author: \\ Email: drdhananjaybs@gmail.com
}

Received: $5^{\text {th }}$ June, 2018

Accepted: $12^{\text {th }}$ June, 2018

\begin{abstract}
Introduction: Pregnancy and child birth though considered as physiological process can become lethal for any woman. Childbirth was considered as rebirth to a woman in olden era. The atmost duty of an Obstetrician is to identify the abnormal events at the earliest, intervene appropriately and avoid the catastrophe. The importance of partogram is to prevent the maternal and perinatal complications. The World Health Organisation has simplified the partogram for its use by skilled birth attendants.

Aims and Objectives: To study the progress and outcome of labour using modified WHO partogram in pontaneous labour in primigravidas.

Materials and Methods: A cross sectional study of 200 women primigravidas admitted to Sree Siddhartha Medical College from December 2016 to November 2017 with spontaneous onset of labour at term with no high risk factors were recruited for the study using modified WHO Partogram.

Augmentation of labour requirement, duration of active labour, mode of delivery, maternal and perinatal outcome were studied. Patients were divided into 2 groups - Group 1 and Group 2. Group 1- cervical dilatation and descent curve falling to the left of the alert line. Group 2- cervical dilatation and descent curve falling to the right of the alert line. Though Group 3 with women to right of action line was planned, there were no patients in group 3.

Results: Most women belonged to age group of 21-25 years. The mean gestational age was 38.2 weeks. In Group 1, the mean duration of active phase of first stage of labour was $4.52 \pm 0.10$ hours, where as it was $5.94 \pm 1.46$ hours in Group 2. In Group 2, the mean duration of second stage of labour was $45.44 \pm 1.94$ mins but it was $34.42 \pm 16.41$ mins in Group 1 study subjects. Mean rate of cervical dilatation is $1.2 \mathrm{~cm} / \mathrm{hr}$. Seventy seven percent had normal delivery, $11 \%$ had caesarean delivery and $12 \%$ had instrumental delivery. Patient crossing the alert line had longer duration of labour. Augmentation was significantly higher in Group $2(92.3 \%)$ than in Group $1(67.8 \%)$. In the study group, there were no maternal and perinatal deaths.

Conclusion: The partograph is an inexpensive and easily accessible tool that can effectively monitor the progress of labour. The WHO simplified partograph is highly useful in identifying when to intervene and also reduces perinatal and maternal mishaps.
\end{abstract}

Keywords: WHO partogram, Alert line, Maternal outcome, Perinatal outcome.

\section{Introduction}

Labour is a natural physiological process characterized by progressive increase in the frequency, intensity and duration of uterine contractions resulting in progressive effacement and dilatation of cervix with the descent of fetal head through the birth canal. But this journey of the fetus through the birth canal can be extremely dangerous leading to morbidity and mortality of both mother and fetus.

Active-labor phase abnormalities are quite common. Sokol ${ }^{1}$ and co-workers (1977) reported that 25 percent of nulliparous labors were complicated by active-phase abnormalities, whereas 15 percent of multigravidas developed this problem. Turning back to Friedman $^{2}$ (1955), the mean duration of active-phase labor in nulliparas was 4.9 hours. The standard deviation of 3.4 hours is quite large. Hence, the active phase was reported to have a statistical maximum of 11.7 hours.

A partogram is a graphical representation of progress of labour. Philpott ${ }^{3}$ in 1971 designed partogram in Zimbabwe. It has been modified and simplified for use by WHO in 2000 for its use by skilled birth attendants. The availability of this partogram was considered an important advance in modern obstetrics and is applicable to low as well as high resource settings. So a partogram aids for the early diagnosis and management of pathological labour. Partogram is a pictorial overview of maternal and fetal condition as well as progression of labour. It aids the systematic approach with careful diagnosis, regular assessment and decisive actions like amniotomy, augmentation of labour with oxytocin and caesarean section. Since it is colour coded and simplified, its use in primary health centres by skilled birth attendants is made easy to recognize the labor abnormalities, intervene in necessary situations and refer to higher centres before the mishaps. The Cochrane database in 2009 has recommended the partogram in developing countries. ${ }^{4}$

The aim and objective of the study was to analyse the primigravidas with spontaneous labour using WHO modified partogram and study their outcome. 


\section{Materials and Methods}

A cross sectional study of 200 women primigravidas in Sree Siddhartha Medical College from December 2016 to November 2017 with spontaneous onset of labour at term with no high risk factors using modified WHO Partogram.

\section{Inclusion Criteria}

1. Primigravidas

2. Singleton pregnancy

3. Term gestation

4. Vertex presentation

Exclusion criteria

1. Multiple gestation

2. Malpresentations and malpositions

3. Contracted pelvis and major degree CPD

4. Obstetric complications like PIH, GDM, APH
5. Medical disorders in pregnancy

Patients were divided into 3 groups - Group 1, Group 2, Group 3. Group 1- cervical dilatation and descent curve falling to the left of the alert line. Group 2- cervical dilatation and descent curve falling to the right of the alert line. Group 3 - cervical dilatation and descent curve falling to the right of the action line

Requirement of Augmentation, duration of labour, mode of delivery, maternal morbidity and neonatal outcome were studied.

\section{Results}

Two hundred primigravidas in spontaneous onset active labour were analysed using WHO simplified partogram. Group 1 consisted of 174 patients, group 2 had 26 patients. There were no patients in Group 3.

Table 1: Age distribution

\begin{tabular}{|l|c|c|c|}
\hline \multicolumn{1}{|c|}{ Age in years } & Group 1 & Group 2 & Total \\
\hline$<20$ & $23(13.2 \%)$ & $3(11.5 \%)$ & 26 \\
\hline $21-25$ & $96(55.3 \%)$ & $18(69.2 \%)$ & 114 \\
\hline $26-30$ & $25(14.45 \%)$ & $4(15.4 \%)$ & 29 \\
\hline$>30$ & $1(0.05 \%)$ & $1(3.9 \%)$ & 2 \\
\hline Total & 174 & 26 & 200 \\
\hline
\end{tabular}

Augmentation of Labour: In Group 1, 118(67.8\%) patients required augmentation where as 66 patients did not require augmentation. In Group 2, 24(92.3\%) patients required augmentation but 2 patients did not require augmentation. So the requirement of augmentation in Group 2 was significantly higher ( $p$ value $<0.05$ ) than Group 1

Table 2: Duration of labour

\begin{tabular}{|l|c|c|}
\hline \multicolumn{1}{|c|}{ Duration of 1st stage } & Mean \pm SD & \\
\hline Group 1 & $4.52 \pm 0.10$ & P value $<0.001$ \\
\cline { 1 - 2 } Group 2 & $5.94 \pm 1.46$ & Highly Significant \\
\cline { 1 - 2 } Duration of 2nd stage & Mean \pm SD & \\
\hline Group 1 & $34.42 \pm 16.41$ & P value $<0.001$ \\
\cline { 1 - 2 } Group 2 & $45.44 \pm 1.94$ & Highly Significant \\
\hline
\end{tabular}

Table 3: Mode of delivery

\begin{tabular}{|c|c|c|c|c|}
\hline & Group 1 & Group 2 & Total & \multirow{4}{*}{$\begin{array}{l}\mathrm{P} \text { value } \\
<0.001\end{array}$} \\
\hline Vaginal (Normal+Instrumental) & $166(95.4 \%)$ & $12(46.2 \%)$ & $178(89 \%)$ & \\
\hline LSCS & $8(4.6 \%)$ & $14(53.8 \%)$ & $22(11 \%)$ & \\
\hline Total & 174 & 26 & 200 & \\
\hline
\end{tabular}

Table 4: Indications for LSCS

\begin{tabular}{|l|c|c|}
\hline \multicolumn{1}{|c|}{ Indications } & Group 1 & Group 2 \\
\hline CPD & 5 & 0 \\
\hline Fetal Distress & 2 & 5 \\
\hline Deep Transverse Arrest & 0 & 4 \\
\hline Protracted Dilatation & 0 & 3 \\
\hline Arrest of Descent & 1 & 2 \\
\hline Total & 8 & 14 \\
\hline
\end{tabular}

Indications for Instrumental Deliveries: Failure of secondary forces and fetal distress were the indications of instrumental deliveries. Vacuum deliveries were conducted in 10 patients in Group 1 and 5 patients in Group 2. Six cases of fetal distress in Group 1 and 3 
cases of fetal distress in Group 2 were the indications of instrumental vaginal deliveries

Perinatal Outcome: There were 6 NICU admissions in Group 1 and 1 NICU admissions in Group 2.

The APGARS were good (8-10) in 164 newborns $(94.25 \%)$ in Group 1and in 23 newborns $(88.5 \%)$ in Group 2. APGARS $<7$ was seen in 10 newborns (5.75\%) and 3 newborns in Group 1 and Group 2 respectively. However this was not statically significant, $\mathrm{p}-0.26$.

In the study group, there were no maternal and perinatal deaths.

\section{Discussion}

Two hundred primigravidas in spontaneous onset active labour were analysed using WHO simplified Partogram. Group 1 consisted of 174 patients, group 2 had 26 patients. There were no patients in Group 3. In a similar type of study by Lakshmi Devi et al, ${ }^{5} 66.5 \%$ patients belonged to Group 1, 20\% TO Group 2 and $13.5 \%$ to group 3 .

Majority of study subjects belonged to age group of 21-25 years. This is similar to studies Pujar, et al. ${ }^{6}$

In our study, Augmentation of labour was required in $92.3 \%$ in Group 2 and was significantly higher than Group $1(67.8 \%), p$ value $<0.05$. In a similar type of study by Penumadu KM et al, ${ }^{7}$ augmentation was significantly higher in Group 3(96\%) and Group 2 (68.4\%) than Group 1 (26.2\%).

In the study, the caesarean section rate was $11 \%$. The instrumental deliveries constituted $12 \%$ and the rest $77 \%$ were Full term normal deliveries (FTND). This is similar to the study by Usha Rani et al, ${ }^{8}$ who has quoted the caesarean rate of $18 \%$. In the WHO study, 78.3\% had FTND, $14.7 \%$ instrumental deliveries and $5.4 \%$ caesarean sections. In a study by Sundaravani, ${ }^{9}$ Caesarean section rate was $24.6 \%$ in primigravida and the rate of the instrumental vaginal delivery in primigravida was $4.6 \%$

The mean duration of first stage and second stage was $4.52 \pm 0.10 \mathrm{hrs}, 5.94 \pm 1.46 \mathrm{hrs}$ and $34.42 \pm 16.41 \mathrm{~min}$, $45.44 \pm 1.94 \mathrm{~min}$ in Group 1 and Group 2 respectively. Labour was completed within 12 hours in all patients. This coincides with the results of the study by Kavya Mendu Penumadu et al, ${ }^{7}$ who quoted the mean duration of 1st stage of labour was 4.2 hours and 6.4hrs in Group A and Group B respectively and there was no significant difference between the groups regarding second stage of labour.

There were 6 NICU admissions in Group 1 and 1 NICU admissions in Group 2. This was not statistically significant in the study. In a study by Sureka Tayade, ${ }^{10}$ there was significant reduction in neonatal intensive care admissions from $17 \%$ in control (non partograph) group to $6 \%$ in babies where partograph was used.

\section{Conclusion}

Maternal and perinatal outcome was better in those who did not cross the alert line.

The partograph is an inexpensive and easily accessible tool that can effectively monitor the progress of labour. The WHO simplified partograph is highly useful in identifying when to intervene and also reduces perinatal and maternal complications.

\section{References}

1. Sokol RJ, Stojkov J, Chik L, et al: Normal and abnormal labor progress: I. A quantitative assessment and survey of the literature. J Reprod Med. 18:47,1977. [PMID: 833800]

2. Friedman EA: Primigravid labor: A graphicostatistical analysis. Obstet Gynecol. 1955:6:567. [PMID: 13272981]

3. Philpott, R.H., and Castle, W.M. Cervicographs in the management of labour in Primigravidae. Int J Gynecol Obstet 1972;79(7):592-98.

4. Lavender T, Hart A, Smyth RM. Effect of partogram use on outcomes for women in spontaneous labour at term. Cochrane Database Syst Rev. 2008;8(4):CD005461

5. Lakshmidevi, Muralidhar, K. V. Malini, and Vishma H. Shetty. "Partographic Analysis of Spontaneous Labour at Term in Primigravida." Journal of Obstetrics and Gynaecology of India 62.6 (2012):635-640.

6. Kavitha G. Pujar, Shruthi V. Salian, Sunanda R. Kulkarni. Partographic analysis of labour by modified who partograph in primigravidae: a prospective observational study. Int J Reprod Contracept Obstet Gynecol. 2016;5(1):166-169.

7. Role of partogram in the management of spontaneous labour in primigravida and multigravidas. Penumadu KM, Hariharan International Journal of Reproduction, Contraception, Obstetrics and Gynecology,. Int J Reprod Contracept Obstet Gynecol. 2014;3(4):1043-1049.

8. Usha Rani, B Vijaya Laxmi. Effect of partographic monitoring on outcomes for women in spontaneous labour at term. IAIM, 2016; 3(7):314-320.

9. Sundaravani C, Nesam Susanna Minnalkodi Comparitive Analytical Study of Role of Partograph in Primigravida versus Multigravida. International Journal of Scientific Research, 2015;4(12).

10. Surekha Tayade. The impact of modified WHO Partogram on Maternal and Perinatal Outcome. International Journal of Biomedical and Advance Research IJBAR. (2012) 03(04).

How to cite this article: Gopinath $\mathrm{S}$, Dhananjaya B S, Krishna C. Role of who modified partograph in management of spontaneous labour in primigravidas. Ind $\mathbf{J}$ Obstet Gynecol Res. 2018;5(3):381-383. 